\title{
Alternating Phosphorylation with O-GIcNAc Modification: Another Way to Control Protein Function
}

\author{
Victor V. Lima and Rita C. Tostes* \\ Department of Pharmacology, School of Medicine of Ribeirao Preto, \\ University of Sao Paulo, Ribeirao Preto-SP, \\ Brazil
}

\section{Introduction}

As widely known, reversible phosphorylation of proteins, or the addition of a phosphate (PO43-) molecule to a polar $\mathrm{R}$ group of an amino acid residue, is an important regulatory mechanism that switches many enzymes and receptors "on" or "off" and therefore controls a range of cellular functions. Regulatory roles of phosphorylation include biological thermodynamics of energy-requiring reactions, enzyme and receptors' activation or inhibition, protein-protein interaction via recognition domains, protein degradation.

Kinases and phosphatases are involved in this process and these enzymes induce phosphorylation and dephosphorylation, respectively, of target proteins. Phosphorylation usually occurs on serine, threonine, and tyrosine (O-linked), or histidine ( $N$-linked) residues of proteins, although arginine and lysine residues can also be phosphorylated.

$\mathrm{O}$-GlcNAcylation, or glycosylation with $\mathrm{O}$-linked $\beta$-N-acetylglucosamine, is similar to protein phosphorylation in that both modifications occur on serine and threonine residues, both are dynamically added and removed in response to cellular signals, and both alter the function and associations of the modified protein. O-GlcNAcylation also modulates many cellular functions by mechanisms that include protein targeting to specific substrates, transient complex formation with other proteins, subcellular compartmentalization upon glycosylation of specific proteins and a complex interplay with protein $O$-phosphorylation, the main topic of this chapter. Accordingly, in this chapter we will discuss the biology of the $O$-GlcNAc modification, the interplay between $O$-GlcNAcylation and $O$-phosphorylation, signaling pathways modified by $O$-GlcNAcylation, and the physiological implications of alternating $O$-GlcNAcylation and $O$-phosphorylation.

\section{The biology of the O-GIcNAc}

Glycosylation is the site-specific enzymatic addition of saccharides [from the Greek word sákkharon (meaning sugar); also known in biochemistry as carbohydrates or hydrates of

* Corresponding Author 
carbon due to the chemical empirical formula $\left.\mathrm{C}_{\mathrm{m}}\left(\mathrm{H}_{2} \mathrm{O}\right)_{n}\right]$ to proteins and lipids. Glycosylation has many functions in a cell: it allows correct folding of proteins (some proteins do not fold correctly unless they are glycosylated first); confers stability (some unglycosylated proteins are more rapidly degraded); allows cell-cell adhesion (e.g. surface glycoproteins are directly involved in the biological functions of lymphocytes); and modulates intracellular signaling pathways (glycosylation of proteins may enhance or inhibit enzymes' activities) (Spiro, 2002; Taylor \& Drickamer, 2006; Varki et al., 2009).

There are many types of glycosylation: $N$-linked, where the carbohydrate is attached to a nitrogen of asparagine or arginine side-chains; $O$-linked, where glycans are attached to the hydroxy oxygen of serine, threonine, tyrosine, hydroxylysine, or hydroxyproline sidechains; phospho-linked, where the sugar is attached via the phosphate of a phospho-serine; $C$-linked, where the carbohydrate is added to a carbon on a tryptophan side-chain; the formation of a glycosylphosphatidylinositol (GPI) anchor (glypiation), where the sugar is linked to phosphoethanolamine, which in turn is attached to the terminal carboxyl group of the protein (Spiro, 2002; Taylor \& Drickamer, 2006; Varki et al., 2009). However, great interest has been directed to O-GlcNAcylation, or glycosylation of proteins with $O$-linked $\beta$ N-acetylglucosamine.

Cellular glycoproteins were initially thought to be targeted, after their synthesis, only to luminal or extracellular compartments. However, in 1984, Torres and Hart, who were interested in characterizing the role of cell-surface saccharides in the development and functions of lymphocytes, described a novel carbohydrate (N-acetylglucosamine, GlcNAc)peptide linkage, which was present on proteins localized in the cytosol and the cyto- and nucleoplasmic faces of membranous organelles (Torres \& Hart, 1984). In 1989, Kelly and Hart described that Drosophila polytene chromosomes (i.e., polytene chromosome spreads prepared from the salivary glands of third instar stage Drosophila melanogaster larvae) contained a surprisingly large amount of terminal GlcNAc residues along their lengths. Nearly all of the chromatin-associated GlcNAc moieties existed as single monosaccharide residues attached to protein by an O-linkage (O-GlcNAc) (Kelly \& Hart, 1989). Also in the late 80 's, the glycosyltransferase responsible for the addition of GlcNAc to proteins was found to be oriented with its active site in the cytoplasm and the first proteins modified with O-GlcNAc were described (Hart et al., 1988, 1989; Hart, 1997). These initial observations, which indicated a functional or biological significance for the $O$-linkage of GlcNAc to proteins, led to the term O-GlcNAcylation. Accordingly, O-GlcNAcylation is currently defined as an unusual form of protein glycosylation, where a single-sugar [Nacetylglucosamine (O-GlcNAc)] is added ( $\beta$-attachment) to the hydroxyl moiety of serine (Ser) and threonine (Thr) residues of nuclear and cytoplasmic proteins.

It is unusual in that it is found in nuclear and cytoplasmic proteins, representing the first reported example of glycosylated proteins found outside of the secretory channels. Unlike other peptide-linked monosaccharides, the $\beta$-linked GlcNAc-Ser/Thr does not become further substituted by other sugars, remaining a single monosaccharide modification of the protein to which it is attached. O-GlcNAcylation is widely dispersed among eukaryotes, from protozoa to higher mammals. The amino acid consensus sequence or glycosylation motifs for the formation of O-GlcNAc bonds have not yet been found. However, information relating to the polypeptide domains that favors $O$-GlcNAc attachment has been obtained and seems to involve PEST [proline $(\mathrm{P})$, glutamic acid (E), serine $(\mathrm{S})$, and threonine (T)] sequences (Haltiwanger et al., 1997; Rogers et al., 1986). 
Results from recent proteomic studies, from different laboratories, suggest that more than 1500 proteins in the cell are modified by O-GlcNAc. These proteins belong to almost every functional class of proteins including transcription or translation factors, cytoskeletal proteins, nuclear pore proteins, RNA polymerase II, tumor suppressors, hormone receptors, phosphatases, and kinases (Khidekel et al., 2007; Nandi et al., 2006; Wang et al., 2008; Vosseller et al., 2006). A database of O-GlcNAcylated proteins and sites, dbOGAP, was recently created and is primarily based on literature published since $O$-GlcNAcylation was first described in 1984. The database currently contains $\sim 800$ proteins with experimental $O-$ GlcNAcylation information. The $O$-GlcNAcylated proteins are primarily nucleocytoplasmic, and include membrane- and non-membrane bounded organelle-associated proteins (Wang et al., 2011). An O-GlcNAcylation site prediction system (O-GlcNAcScan) based on nearly 400 O-GlcNAcylation sites was also developed $(\mathrm{Hu}, 2010)$. Both the database and the prediction system are publicly available at $h t t p: / / c b s b$.lombardi.georgetown.edu/OGAP.html and http://cbsb.lombardi.georgetown.edu/filedown.php, respectively.

The attachment of the single-sugar $B-N$-acetylglucosamine via an $O$-linkage to Ser/Thr residues is controlled by two highly conserved enzymes, O-GlcNAc transferase (OGT or uridine diphospho- $\mathrm{N}$-acetyl glucosamine; polypeptide $\beta$-N-acetylglucosaminyl transferase; UDP-NAc transferase) and $\beta$-N-acetylglucosaminidase (OGA or O-GlcNAcase). Whereas OGT catalyses the addition of $O$-GlcNAc to the hydroxyl group of Ser and Thr residues of a target protein using UDP-GlcNAc as the obligatory substrate, OGA catalyses the hydrolytic cleavage of $O$-GlcNAc from post-translationally-modified proteins (Hart et a;, 2007; Zachara \& Hart, 2006) (Figure 1).

A single OGT gene is located on the X chromosome in humans and mice (Kreppel et al., 1997; Nolte \& Muller, 2002). In some tissues, such as skeletal muscle, kidney, and liver, three distinct isoforms of OGT have been identified, including two 110-kDa subunits and one 78$\mathrm{kDa}$ subunit, which can assemble into multimers, and smaller mitochondrial isoforms (Kreppel \& Hart, 1999, Lazarus et al., 2006; Lubas \& Hanover, 2000). Each variant contains a C-terminal catalytic domain, but differs in the number of tetratricopeptide repeats (TPRs) within its N-terminal domain. The TPRs serve as protein-protein interaction modules that appear to target OGT to accessory proteins and potential substrates, such as the related $O$ GlcNAc transferase interacting protein (OIP106) and protein phosphatase-1 (PP1) (Wells et al., 2004). Phylogenetic analysis of eukaryotic OGTs indicate that plants have two distinct OGTs, SEC (secret agent)- and SPY (spindly)-like, that originated in prokaryotes and that are involved in diverse plant processes, including response to hormones and environmental signals, circadian rhythms, development, intercellular transport and virus infection (Olszewski et al., 2009; Swain et al, 2001). Animals and some fungi have a SEC-like enzyme while plants have both. Green algae and some members of the Apicomplexa and amoebozoa have the SPY-like enzyme (Olszewski et al., 2009).

The donor substrate for OGT activity, UDP-GlcNAc or uridine-diphosphate-Nacetylglucosamine, is a terminal product of the hexosamine biosynthesis pathway (HBP Figure 1). Flux through the HBP and UDP-GlcNAc levels changes rapidly in response to many different nutrients, such as glucose, fatty acids, and amino acids (Hanover et al., 2009) altering the extent of $O$-GlcNAcylation of many proteins. It is estimated that $2-5 \%$ of total cellular glucose is funneled into the HBP, although the glucose flux is potentially different in various cell types (Hart et al., 2007, Hanover et al., 2009). Free fatty acids can increase HBP flux by inhibiting glycolysis, resulting in elevated fructose-6-phosphate levels. Acetyl-CoA, 
produced by fatty acid metabolism, serves as the donor for the acetylation of glucosamine in the formation of UDP-GlcNAc (Wang et al., 1998). Exogenously, small amounts of glucosamine can dramatically increase UDP-GlcNAc pools in cells (Zou et al., 2009).

The HBP shares its first two steps with glycolysis. First, hexokinase phosphorylates glucose to produce glucose 6-phosphate, which is then converted into fructose 6-phosphate. At this point the pathways diverge, fructose 6-phosphate is converted by the HBP rate-limiting enzyme glutamine fructose-6-phosphate transferase (GFAT) into glucosamine 6-phosphate (Slawson et al., 2010). Because OGT activity is exquisitely sensitive to UDP-GlcNAc concentrations (Haltiwanger et al., 1992) (Figure 1), O-GlcNAcylation may act as a sensor for the general metabolic state of the cell.

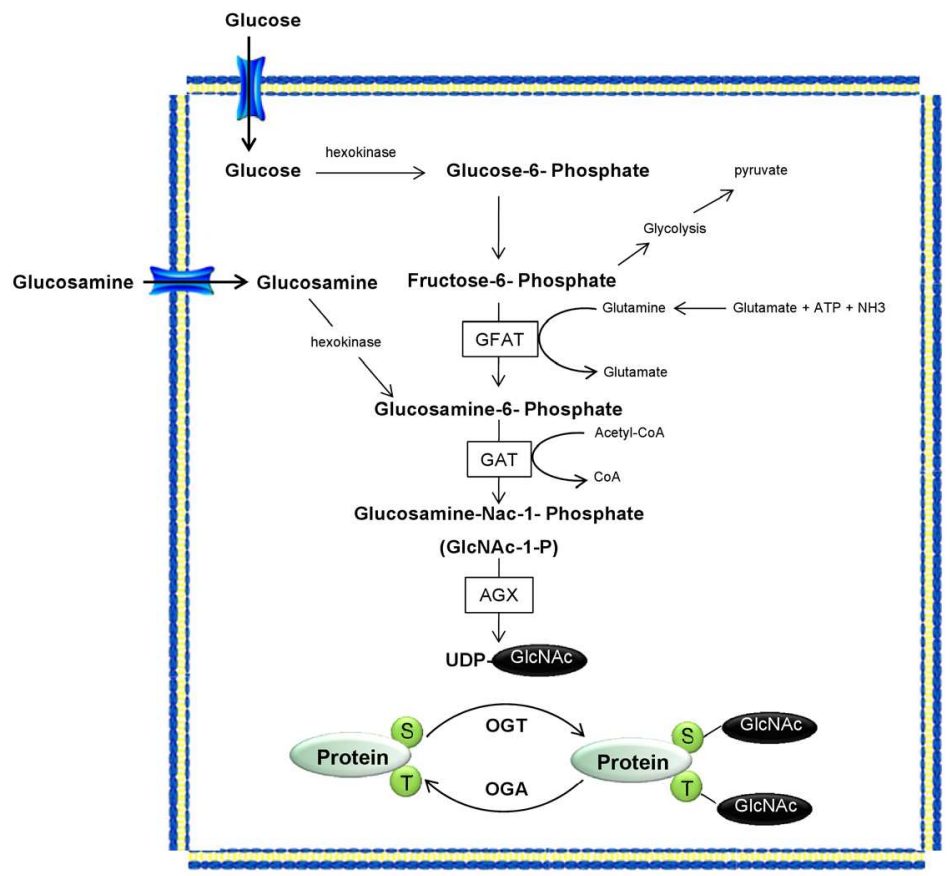

Fig. 1. The hexosamine biosynthesis pathway. After entering the cell via a glucose transporter and being converted to glucose-6-phosphate (glucose-6P) by a hexokinase and to fructose-6phosphate (fructose-6P), glucose can either be used in the glycolytic or the hexosamine biosynthesis (HBP) pathways. The HBP uses fructose-6P to form glucosamine-6-phosphate (glucosamine-6P), with glutamine serving as the donor of the aminogroup. The reaction is catalyzed by the rate-limiting enzyme glutamine:fructose-6-phosphate transferase (GFAT). Glucosamine-6P is rapidly acetylated through the action of acetyl-CoA:d-glucosamine-6phosphate $\mathrm{N}$-acetyltransferase (GAT), and isomerized to N-Acetylglucosamine-1-phosphate (GlcNAc-1-P) and activated, via the action of UDP-GlcNAc pyrophosphorylase (AGX), to UDP-N-acetylglucosamine (UDP-GlcNAc) that serves as the donor of O-GlcNAc for OGT activity. Glucosamine can also enter the cell through the glucose transporter and is rapidly phosphorylated by hexokinase yielding glucosamine-6P, thereby bypassing the rate-limiting first step of the HBP. S, serine; T, threonine, OGT, O-GlcNAc transferase; OGA, O-GlcNAcase. 
O-GlcNAcase or OGA was initially identified as hexosaminidase C. However, OGA activity is specific for $\mathrm{N}$-acetyl- $\beta$-D-glucosaminides and, unlike hexosaminidase, has an optimum pH near neutral and mainly a cytosolic localization (Dong \& Hart, 1994; Zachara \& Hart, 2006). OGA appears to use substrate catalysis involving the 2-acetamido group and contains an N-terminal glycosidase domain and a putative C-terminal histone acetyltransferase domain (Macauley et al., 2005; Toleman et a., 2004). To date, two distinct isoforms of OGA have been described, a $130-\mathrm{kDa}$ and a $75-\mathrm{kDa}$ variant, which differ in their $\mathrm{C}$ terminus. Whereas the 130-kDa or "long OGA" contains a distinct N-terminal glycosidase domain and the C-terminal histone acetyltransferase domain, the 75-kDa or "short OGA" lacks the Cterminal domain. One important functional aspect in the existence of these two splices is their differential sensitivity to previously described potent OGA inhibitors. For example, the short OGA exhibits comparative resistance to PugNAc and NAG-thiazoline, but is very sensitive to alpha-GlcNAc thiolsulfonate (Zachara \& Hart, 2006). Inhibition of OGT and OGA represents an area of great interest on O-GlcNAcylation research, which is evident from the increasing number of studies addressing the enzymes molecular mechanisms for the addition and removal of $O$-GlcNAc (Borodkin \& van Aalten, 2010; Dorfmueller et al., 2010, 2011; Dorfmueller \& van Aalten, 2010; Gloster et al., 2011; Gloster \& Vocadlo, 2010; Lameira et al., 2011; Lazarus et al., 2011; Li et al., 2011; Macauley \& Vocadlo, 2010; MartinezFleites et al., 2010).

\section{The interplay between O-GIcNAcylation and Protein O-Phosphorylation}

The dynamic addition of $O$-GlcNAc to proteins has been implicated in modulating protein behavior via one potential mechanism that includes a complex interplay between $O$ GlcNAcylation and phosphorylation. Many phosphorylation sites are also known glycosylation sites, and this reciprocal occupancy may produce different activities or alter stability in the target protein (Hu et al., 2010; Zeidan \& Hart, 2010) (Figure 2). In support of this model, an earlier report has shown that activation of PKC and PKA reduced glycosylation in a detergent insoluble cytoskeletal and cytoskeleton-associated protein fraction. Conversely, inhibition of PKC and PKA increased O-GlcNAc protein modification in this fraction (Griffith \& Schmitz, 1999). The competition between O-GlcNAcylation and phosphorylation for the same or neighboring residues has been termed the "yin-yang" hypothesis and has been reported in a variety of proteins (Hart et al., 1995).

However, it should be emphasized that the interplay between these two PTMs is not always reciprocal. For example, some proteins, such as p53 and vimentin, can be concomitantly phosphorylated and O-GlcNAcylated, and the adjacent phosphorylation or OGlcNAcylation can regulate the addition of either moiety (Wang et al., 2007; Yang et al., 2006).

In addition to the reciprocal crosstalk at same or proximal sites of the proteins, crosstalk between $\mathrm{O}$-GlcNAcylation and phosphorylation also exists among distantly located sites, such as on the C-terminal domain of RNA polymerase II and on cytokeratins (Chou et al., 1992; Comer \& Hart, 2001). Furthermore, the crosstalk between phosphorylation and OGlcNAcylation also influences each other by regulating the activities or localization of other cycling enzymes. For example, OGT is directly activated by tyrosine phosphorylation and is 


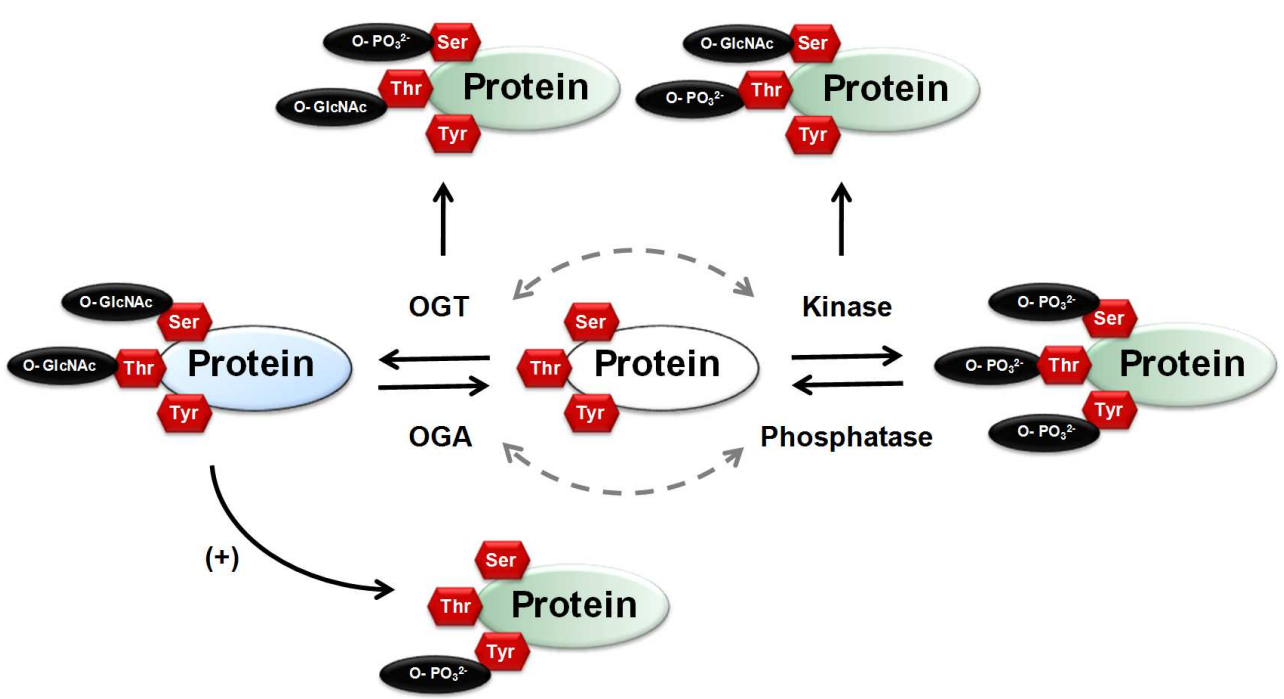

Fig. 2. The interplay between $O$-GlcNAcylation and $O$-phosphorylation of proteins. Both phosphorylation and $O$-GlcNAcylation occur on serine/threonine (Ser/Thr) residues of proteins. In specific proteins, there is a competitive relationship between $O$-GlcNAc and $O$ phosphate for the same Ser/Thr residues, although there can be adjacent or multiple occupancy for phosphorylation and $O$-GlcNAcylation on the same protein. The interplay between phosphorylation and $O$-GlcNAcylation creates molecular diversity by altering specific protein sites that regulate protein functions and signaling events. OGT, O-GlcNAc transferase; OGA, O-GlcNAcase; Tyr, tyrosine. Reproduced with permission, from Lima et al., 2012, Clinical Science, vol__pp___. ( ) the Biochemical Society.

itself O-GlcNAc-modified [49]. OGT also forms a stable and active complex with protein phosphatase-1 (PP1 $\beta$ and PP1 $\gamma$ ) in rat brain [50]. The association between OGT and PP1 is particularly intriguing, as it may provide a direct mechanism to couple $O$-GlcNAc to dephosphorylation of specific substrates. As with OGT, OGA has been shown to interact with specific proteins, including protein phosphatase-2 $\beta$ (Wells et al., 2002).

A recent report showed that rat brain assembly protein AP180, which is involved in the assembly of clathrin-coated vesicles in synaptic vesicle endocytosis, contains a phosphorylated $O$-GlcNAc $(O-G l c N A c-P)$ within a highly conserved sequence $(O$-GlcNAc or O-GlcNAc-P, but not phosphorylation alone, was found at $\mathrm{Thr}^{310}$ ) (Graham et al., 2011). $O$-GlcNAcylation was thought to be a terminal modification, i.e. the O-GlcNAc was not found to be additionally modified. The existence of protein glycosyl phosphorylation $(O-$ GlcNAc-P) adds further complexity to the phosphorylation-O-GlcNAcylation interplay.

Lastly, the interplay between $O$-GlcNAc modification and phosphorylation may not be limited to Ser/Thr phosphorylation, but may also include tyrosine (Tyr) phosphorylation. Based on the higher prevalence of Tyr phosphorylation among O-GlcNAc-modified proteins ( $\sim 68 \%$ vs. $\sim 2 \%$ in non-O-GlcNAc-modified proteins), Mishra and colleagues suggested that Tyr phosphorylation plays a role in the interplay between $O$-GlcNAc modification and Ser/Thr phosphorylation in proteins (Mishra et al., 2011). 
This clearly shows that the interplay between O-GlcNAcylation and phosphorylation is both complex and very extensive. As with any PTM, mapping the attachment sites is a prerequisite toward understanding the biological functions of O-GlcNAcylation. With the development of sample enrichment methods and new mass spectrometry fragmentation methods, such as electron capture dissociation and electron transfer dissociation, now hundreds of $O$-GlcNAc sites have been mapped, and some cellular stimuli were shown to increase both modifications. For further information on the complex interplay between $O-$ GlcNAcylation and phosphorylation, please refer to the following comprehensive and excellent reviews (Copeland et al., 2008; Hart et al., 2011; Hu et al., 2010; Wang et al., 2008; Zeidan \& Hart 2010).

\section{Signaling pathways modified by 0 -GIcNAcylation}

Many proteins, mainly kinases, involved in signaling pathways that regulate cell growth, apoptosis, ion channel activities, and actin cytoskeleton are target for O-GlcNAc modification (Lima et al., 2009, 2011). In this section we will briefly comment general aspects of some of the signaling proteins that have been identified as targets for $\mathrm{O}$-GlcNAcylation.

The protein kinase $\mathrm{C}(\mathrm{PKC})$ family constitutes a group of multifunctional Ser/Thr protein kinases that are classified into three groups: the classic PKCs [PKCalpha $(\alpha), \operatorname{PKCbeta}(\beta \mathrm{I})$, PKCbeta( $(\beta I I), \operatorname{PKCgamma}(\gamma)]$, the novel PKCs [PKCdelta( $(\delta), \operatorname{PKCepsilon}(\varepsilon), \operatorname{PKCeta}(\eta)$, $\operatorname{PKCmu}(\mu)$, PKCtheta $(\theta)$ ], and the atypical PKCs [PKCzeta $(\zeta)$, PKCiota/lambda $(1 / \lambda)$ ] (Salamanca \& Khalil, 2005).

Functional studies have demonstrated that interaction of PKC with its protein substrate triggers activation of a cascade of kinases that ultimately stimulate many cellular functions, including contraction, hypertrophy, growth, proliferation and cell survival. As an example, PKC phosphorylates CPI-17, which in turn inhibits myosin light chain (MLC) phosphatase, increases MLC phosphorylation and enhances vascular smooth muscle contraction. PKC also phosphorylates the actin-binding protein calponin, and thereby reverses its inhibition of actin-activated myosin ATPase, allowing more actin to interact with myosin and increases vascular contraction (Budzyn et al., 2006; Salamanca \& Khalil, 2005; Woodsome et al, 2001).

Initial studies indicated that activation of PKC or cAMP-dependent protein kinase significantly decreased overall $\mathrm{O}-\mathrm{GlcNAcylation}$ in neuronal cytoskeletal proteins. Conversely, inhibition of PKC, cAMP-dependent protein kinase, cyclin-dependent protein kinases, or S6 kinase increased overall O-GlcNAc levels in fractions from these cells (Griffith et al., 1995). Stimulation of the transactivation of Sp1, which is O-GlcNAcylation-dependent, can be blocked by molecular and pharmacological inhibition of PKC (Fantus et al., 2006). In cerebellar neurons from early postnatal mice, activation of cAMP-dependent protein kinase or PKC results in reduced levels of $O$-GlcNAc specifically in the fraction of cytoskeletal and cytoskeleton-associated proteins, whereas inhibition of the same kinases results in increased levels of O-GlcNAc (Griffith \& Schmitz, 1999).

In the reverse direction, all PKC isoforms expressed in rat hepatocytes are dynamically modified by O-GlcNAc. O-GlcNAcylation of PKC-a negatively correlates with enzyme activity (Robles-Flores et al., 2008). Increased O-GlcNAc modification in a human astroglial cell line, in response to glucosamine (which increases the production of glucosamine 6phosphate and stimulates $\mathrm{O}$-GlcNAc modification of proteins) or PUGNAc (which blocks $\mathrm{O}$ - 
GlcNAcase activity, mimicking the enzyme-stabilized transition state), results in a decrease in membrane-associated PKC- $\varepsilon$ and PKC- $\alpha$, but not PKC- - , indicating that increased levels of the O-GlcNAc modification regulates specific PKC isoforms (Matthews et al., 2005). Therefore, it is likely that $O$-GlcNAc modification of PKC isoforms, such as PKC- $\alpha$, PKC- $\beta$, PKC $-\gamma$, PKC $-\varepsilon$, and PKC- $\zeta$ can interfere with cellular processes regulated by these enzymes.

Mitogen-activated protein kinases (MAPKs) are a family of serine/threonine kinases which are classically associated with cell contraction, migration, adhesion, collagen deposition, cell growth, differentiation, and survival (Pearson et al., 2001). Of the major MAPKs, extracellular signal-regulated kinases (ERK1/2), p38 MAPK, and stress-activated protein kinase/c-Jun N-terminal kinases (SAPK/JNK) are the best characterized. The complex signaling networks that underlie MAPK activation typically require phosphorylation by a MAPK kinase also known as MEK. The ERK1/2 phosphorylation cascade involves MEK1/2 (MAP/ERK kinase) whereas the signaling processes leading to SAPK/JNK and p38 MAPK activation involve MEK4/7 and MEK3/6, respectively (Pearson et al., 2001). Activation of MAPKs has been reported to be primarily dependent on the nonreceptor tyrosine kinase cSrc in different cell types. To date, at least 14 Src-related kinases have been identified, of which the $60 \mathrm{kDa}$ c-Src is the most abundantly expressed isoform in vascular smooth muscle cells and rapidly activated by $\mathrm{G}$ protein-coupled receptors. Other proximal regulators of MEK include the Ras-Raf pathway, which may not necessarily involve c-Src (Kolch, 2005; Martin, 2001; Oda et al., 1999).

The MAPKs p38 and ERK1/2 have been reported to be phosphorylated in response to increased O-GlcNAc levels (Laczy et al., 2009). A positive correlation between phosphorylation of the MAPK cascade (ERK1/2 and p38) and nuclear O-GlcNAcylation was observed in fetal human cardiac myocytes exposed to high glucose (Gross et al., 2005). In isolated rat hearts, perfusion with $5 \mathrm{mM}$ glucosamine increases $O$-GlcNAc levels and confers cardioprotection after ischemia-reperfusion (Zou et al., 2009). Interestingly, although glucosamine does not alter the response of either ERK1/2 or Akt (protein kinase B) to ischemia-reperfusion, it significantly attenuates the ischemia-induced increase in p38 phosphorylation, as well as the increased p38 phosphorylation at the end of reperfusion, suggesting that glucosamineinduced cardioprotection may be mediated via the p38 MAPK pathway (Jones et al., 2008).

Augmented $O$-GlcNAc levels in mouse hippocampal synapses increases phosphorylation of synapsin I/II at Ser ${ }^{9}$ (cAMP-dependent protein kinase substrate site), Ser62/67 (ERK1/2 [MAPK 1/2] substrate site), and Ser603 (calmodulin kinase II site). Activation-specific phosphorylation events on ERK1/2 and calmodulin kinase II are also increased in response to elevation of $O$-GlcNAc levels (Rexach et al., 2008).

Advanced glycation end-products induce ROS accumulation, apoptosis, MAPK activation, and nuclear O-GlcNAcylation in human cardiac myocytes (Li et al., 2007). In addition, exposure of neutrophils to PUGNAc or glucosamine also stimulates the small GTPase Rac, which is an important upstream regulatory element in p38 and ERK1/2 MAPK signaling in neutrophils, and these MAPKs are implicated in chemotactic signal transduction.

Conversely, alterations in MAPK pathways can also have effects on the enzymes responsible for the regulation of O-GlcNAc (Laczy et al., 2009, Lima et al., 2011). In neuro-2a neuroblastoma cells, increased OGT expression on glucose deprivation occurs in an AMPactivated protein kinase-dependent manner, whereas OGT enzymatic activity is regulated 
in a p38 MAPK-dependent manner. OGT is not phosphorylated by p38, but rather it interacts directly with $\mathrm{p} 38$ through its $\mathrm{C}$ terminus. The interaction with $\mathrm{p} 38$ does not change the catalytic activity of OGT, but p38 regulates OGT activity within the cell by recruiting it to specific targets (Cheung \& Hart, 2008).

Together, these data indicate that $O$-GlcNAcylation is an important signaling element and it modulates the activities of several critical signaling kinases (Kneass \& Marchase, 2005). Thus, it is possible that signaling kinases, such as proteins from MAPK, PKC, and RhoA/Rho kinase pathways, are also regulated by O-GlcNAc modifications and that this post-translational modification not only modulates many cellular responses, but also may play a role in the abnormal function of kinases observed in various pathological conditions.

$\mathrm{Ca}^{+2}$ sensitization in smooth muscle cells is a well known process mediated by the small GTPase Rho and its downstream target Rho-kinase. The exchange of bound guanosine diphosphate (GDP) for guanosine triphosphate (GTP) activates Rho and stimulates its translocation from the cytosol to the plasma membrane. Rho-GTP phosphorylates Rhokinase, which inhibits MLC phosphatase activity by phosphorylation of the MLC phosphatase target subunit (MYPT1). A decrease in MLC phosphatase activity increases phosphorylation of myosin and therefore contributes to smooth muscle contraction at low levels of intracellular $\mathrm{Ca}^{+2}$ (Somlyo \& Somlyo, 2000). RhoA/Rho kinase signaling has been implicated in many cellular processes including contraction, reactive oxygen species generation, inflammation, and cell migration (Calo \& Pessina, 2007).

Rho-kinase activation also suppresses eNOS activity/expression, and decreased sensitivity of contractile proteins to $\mathrm{Ca}^{2+}$ is considered a key mechanism in NO-induced relaxation of vascular smooth muscle cells. Accordingly, $\mathrm{NO}$ also induces vasodilation through the inhibition of the RhoA/Rho-kinase signaling pathway. Accordingly, NO-mediated increases in cGMP and activation of cGMP-dependent protein kinase (cGK) lead to inhibition of RhoA (Chitaley \& Webb, 2002; Sauzeau et al., 2001; Sawada et al., 2001).

The small G-protein RhoA and its downstream target, Rho-kinase, play a direct role in the regulation of MLC phosphatase activity. In the active state, RhoA engages downstream effectors, such as Rho-kinase, which then phosphorylates the myosin binding subunit of MLC phosphatase (MYPT1 $\mathrm{Thr}^{853}$ ), inhibiting its activity, and thus promoting the phosphorylated state of MLC (Chitaley et al., 2001). Data from our laboratory and others indicate that increased $O$-GlcNAcylation augments vascular reactivity to constrictor stimuli via changes in the RhoA/Rho-kinase pathway (Lima et al, 2011; Kim et al, 2011).

Since increased O-GlcNAcylation decreases eNOS/NO signaling (Musick et al., 2005) and NO inhibits RhoA/Rho-kinase signaling, increased RhoA/Rho-kinase activity observed in many pathological conditions may be associated with augmented $O$-GlcNAc levels.

\section{Physiological implications of alternating $O-$ GIcNAcylation and $O$ - phosphorylation}

The physiological significance of the crosstalk between O-GlcNAcylation and Ophosphorylation certainly warrants further investigation. However, data available so far indicate that the "on" or "off" state of many enzymes and receptors are not simply determined by the kinases- and phosphatases-driven phosphorylation of specific aminoacid residues. The 
complex interplay between O-GlcNAcylation and O-phosphorylation, within reciprocal or proximal sites, makes the activation/deactivation or the "on" /" off" switch of enzymes and receptors a much more elaborated process. Since both post-translational modifications modulate many cellular functions via protein targeting to specific substrates, transient complex formation with other proteins, subcellular compartmentalization of specific proteins, activation/inhibition of many signaling pathways, the interplay between O-GlcNAcylation and O-phosphorylation adds great complexity to our knowledge of protein activity regulation.

New techniques allowing the recognition of several $O$-GlcNAc sites will further clarify how different cellular stimuli interfere with these post-translational modifications. One big challenge in the field has been to map the sites where the attachments are simultaneously occurring. The development and improvement of some techniques such as electron capture dissociation and electron transfer dissociation has opened new possibilities to map $O$ GlcNAcylation and $\mathrm{O}$-phosphorylation sites. Please, refer to the following comprehensive and excellent reviews for further information regarding O-GlcNAc enrichment methods (Macauley \& Vocadlo, 2009; 120. Peter-Katalinic, 2005; Wang et al, 2010; Zachara, 2009).

\section{Conclusions}

Our understanding of the $O$-GlcNAcylation process (enzymatic regulation, cellular targets and sites for O-GlcNAc addition, modulation by other pathways) as well as of its functional importance and its contribution to (dys)regulation of many cellular processes is rapidly increasing. It is also evident that the direct interactions between $O$-GlcNAcylation and $O$ phosphorylation and the fact that both post-translational modifications can interfere with many signaling pathways and cellular processes, not only add great complexity to our knowledge of protein activity regulation, but warrant intense research in the field.

Future investigations focusing on the characterization of specific O-GlcNAcylated and $O$ phosphorylated sites/proteins, as well as studies addressing and identifying the factors involved in the regulation of OGT and OGA activity are needed. They will provide a greater understanding as to how $O$-GlcNAc modulates cellular function and potentially provide an avenue for targeted interventions and therapies.

\section{Acknowledgments}

Financial Support from FAPESP (Fundacao de Amparo a Pesquisa do Estado de Sao Paulo) and CNPq (Conselho Nacional de Desenvolvimento Cientifico e Tecnologico) - Brazil.

\section{References}

Borodkin, V.S. \& van Aalten, D.M. (2010). An efficient and versatile synthesis of GlcNAcstatins-potent and selective O-GlcNAcase inhibitors built on the tetrahydroimidazo[1,2-a]pyridine scaffold. Tetrahedron. 66, pp.7838-7849. ISSN 0040-4020.

Budzyn, K.; Paull, M.; Marley, P.D. \& Sobey, C.G. (2006). Segmental differences in the roles of rho-kinase and protein kinase $\mathrm{C}$ in mediating vasoconstriction. Journal of Pharmacology and Experimental Therapeutics. 317, pp.791-796. ISSN 0022-3565. 
Calo, L.A. \& Pessina, A.C. (2007). RhoA/Rho-kinase pathway: much more than just a modulation of vascular tone. Evidence from studies in humans. Journal of Hypertension. 25, pp.259-264. ISSN 0263-6352.

Cheung, W.D. \& Hart, G.W. (2008). AMP-activated protein kinase and p38 MAPK activate O-GlcNAcylation of neuronal proteins during glucose deprivation. Journal of Biological Chemistry. 283, pp.13009-13020. ISSN 0021-9258.

Chitaley, K. \& Webb, R.C. (2002). Nitric oxide induces dilation of rat aorta via inhibition of rho-kinase signaling. Hypertension. 39, pp.438-442. ISSN 0194-911X.

Chitaley, K.; Weber, D. \& Webb, R.C. (2001). RhoA/Rho-kinase, vascular changes, and hypertension. Current Hypertension Reports 3, pp.139-144. ISSN 1522-6417.

Chou, C.F.; Smith, A.J. \& Omary, M.B. (1992). Characterization and dynamics of O-linked glycosylation of human cytokeratin 8 and 18. Journal of Biological Chemistry. 267, pp.3901-3906. ISSN 0021-9258.

Comer, F.I. \& Hart, G.W. (2001). Reciprocity between O-GlcNAc and O-phosphate on the carboxyl terminal domain of RNA polymerase II. Biochemistry. 40, pp.7845-7852. ISSN 0006-2960.

Copeland, R.J.; Bullen, J.W. \& Hart, G.W. (2008). Cross-talk between GlcNAcylation and phosphorylation: roles in insulin resistance and glucose toxicity. American Journal of Physiology (Endocrinology and Metabolism). 295, pp.E17-E28. ISSN 0193-1849.

Dong, D.L. \& Hart, G.W. (1994). Purification and characterization of an O-GlcNAc selective $\mathrm{N}$-acetyl-beta-D-glucosaminidase from rat spleen cytosol. Journal of Biological Chemistry. 269, pp.19321-19330. ISSN 0021-9258.

Dorfmueller, H.C.; Borodkin, V.S.; Blair, D.E.; Pathak, S.; Navratilova, I. \& van Aalten, D.M. (2011). Substrate and product analogues as human O-GlcNAc transferase inhibitors. Amino Acids. 40, pp.781-792. ISSN 0939-4451.

Dorfmueller, H.C.; Borodkin, V.S.; Schimpl, M.; Zheng, X.; Kime, R.; Read, K.D. \& van Aalten, D.M. (2010). Cell-penetrant, nanomolar O-GlcNAcase inhibitors selective against lysosomal hexosaminidases. Chemistry and Biology. 17, pp.1250-1255. ISSN 1074-552.

Dorfmueller, H.C. \& van Aalten, D.M. (2010). Screening-based discovery of drug-like OGlcNAcase inhibitor scaffolds. FEBS Letters. 584, pp.694-700. ISSN 0014-5793.

Fantus, G.I.; Goldberg, H.J.; Whiteside, C.I. \& Topic, D. (2006). The Hexosamine biosynthesis pathway: Contribution to the pathogenesis of diabetic nephropathy. In: The diabetic kidney, edited by P. C, and C.E. Humana Press, p.120-133. ISBN 978-159745-153-6.

Gloster, T.M. \& Vocadlo, D.J. (2010). Mechanism, structure, and inhibition of O-GlcNAc processing enzymes. Current Signal Transduction Therapy. 5, pp.74-91. ISSN 1574-3624.

Gloster, T.M.; Zandberg, W.F.; Heinonen, J.E.; Shen, D.L.; Deng, L. \& Vocadlo, D.J. (2011). Hijacking a biosynthetic pathway yields a glycosyltransferase inhibitor within cells. Nature Chemical Biology. 7, pp.174-181. ISSN 1552-4450.

Graham, M.E.; Thaysen-Andersen, M.; Bache, N.; Craft, G.E.; Larsen, M.R.; Packer, N.H. \& Robinson, P.J. (2011). A novel post-translational modification in nerve terminals: Olinked N-acetylglucosamine phosphorylation. Journal of Proteome Research. 10, pp.2725-2733. ISSN 1535-3893.

Griffith, L.S. \& Schmitz, B. (1999). O-linked N-acetylglucosamine levels in cerebellar neurons respond reciprocally to pertubations of phosphorylation. European Journal of Biochemistry. 262, pp.824-831. ISSN 0014-2956. 
Griffith, L.S.; Mathes, M. \& Schmitz, B. (1995). Beta-amyloid precursor protein is modified with O-linked N-acetylglucosamine. Journal of Neuroscience Research. 41, pp.270-278. ISSN 0360-4012.

Gross, B.J.; Kraybill, B.C. \& Walker, S. (2005). Discovery of O-GlcNAc transferase inhibitors. Journal of the American Chemistry Society. 127, pp.14588-14589. ISSN 0002-7863.

Haltiwanger, R.S.; Blomberg, M.A. \& Hart, G.W. (1992). Glycosylation of nuclear and cytoplasmic proteins. Purification and characterization of a uridine diphospho-Nacetylglucosamine:polypeptide beta-N-acetylglucosaminyltransferase. Journal of Biological Chemistry. 267, pp.9005-9013. ISSN 0021-9258.

Haltiwanger, R.S.; Busby, S.; Grove, K.; Li, S.; Mason, D.; Medina, L.; Moloney, D.; Philipsberg, G. \& Scartozzi, R. (1997). O-glycosylation of nuclear and cytoplasmic proteins: regulation analogous to phosphorylation? Biochemistry and Biophysical Research Communication. 231, pp.237-242. ISSN 0006-291X.

Hanover, J.A.; Krause, M.W. \& Love, D.C. (2009). The hexosamine signaling pathway: OGlcNAc cycling in feast or famine. Biochimica et Biophysica Acta. 1800, pp.80-95. ISSN 0006-3002.

Hart, G.W. (1997). Dynamic O-linked glycosylation of nuclear and cytoskeletal proteins. Annual Review of Biochemistry. 66, pp.315-335. ISSN 0066-4154.

Hart, G.W.; Greis, K.D.; Dong, L.Y.; Blomberg, M.A.; Chou, T.Y.; Jiang, M.S.; Roquemore, E.P.; Snow, D.M.; Kreppel, L.K.; Cole, R.N., et al. (1995). O-linked N-acetylglucosamine: the "yin-yang" of Ser/Thr phosphorylation? Nuclear and cytoplasmic glycosylation. Advances in Experimental Medical Biology. 376, pp.115-123. ISSN 0065-2598.

Hart, G.W.; Haltiwanger, R.S.; Holt, G.D. \& Kelly, W.G. (1989). Glycosylation in the nucleus and cytoplasm. Annual Review of Biochemistry. 58, pp.841-874. ISSN 0066-4154.

Hart, G.W.; Holt, G.D. \& Haltiwanger, R.S. (1988). Nuclear and cytoplasmic glycosylation: novel saccharide linkages in unexpected places. Trends in Biochemical Sciences. 13, pp.380-384. ISSN 0968-0004.

Hart, G.W.; Housley, M.P. \& Slawson, C. (2007). Cycling of O-linked beta-Nacetylglucosamine on nucleocytoplasmic proteins. Nature. 446, pp.1017-1022. ISSN 0028-0836.

Hart, G.W.; Slawson, C.; Ramirez-Correa, G. \& Lagerlof, O. (2011). Cross Talk Between OGlcNAcylation and Phosphorylation: Roles in Signaling, Transcription, and Chronic Disease. Annual Review of Biochemistry. 80, pp.825-858. ISSN 0066-4154.

$\mathrm{Hu}$, P.; Shimoji, S. \& Hart, G.W. (2010). Site-specific interplay between O-GlcNAcylation and phosphorylation in cellular regulation. FEBS Letters. 584, pp.2526-2538. ISSN 00145793.

Hu, Z.Z. dbOGAP: Database of O-GlcNAcylated Proteins and Sites. (2010) [cited; Available from: http://cbsb.lombardi.georgetown.edu/OGAP.html.

Jones, S.P.; Zachara, N.E.; Ngoh, G.A.; Hill, B.G.; Teshima, Y.; Bhatnagar, A.; Hart, G.W. \& Marban, E. (2008). Cardioprotection by N-acetylglucosamine linkage to cellular proteins. Circulation. 117, pp.1172-1182. ISSN 0009-7322.

Kelly, W.G. \& Hart, G.W. (1989). Glycosylation of chromosomal proteins: localization of Olinked N-acetylglucosamine in Drosophila chromatin. Cell. 57, pp.243-251. ISSN 0092-8674.

Khidekel, N.; Ficarro, S.B.; Clark, P.M.; Bryan, M.C.; Swaney, D.L.; Rexach, J.E.; Sun, Y.E.; Coon, J.J.; Peters, E.C. \& Hsieh-Wilson, L.C. (2007). Probing the dynamics of O- 
GlcNAc glycosylation in the brain using quantitative proteomics. Nature Chemical Biology. 3, pp.339-348. ISSN 1552-4450.

Kim do, H.; Seok, Y.M.; Kim, I.K.; Lee, I.K.; Jeong, S.Y. \& Jeoung, N.H. (2011). Glucosamine increases vascular contraction through activation of RhoA/Rho kinase pathway in isolated rat aorta. BMB Reports. 44, pp.415-420. ISSN 1976-6696.

Kneass, Z.T. \& Marchase, R.B. (2005). Protein O-GlcNAc modulates motility-associated signaling intermediates in neutrophils. Journal of Biological Chemistry. 280, pp.1457914585. ISSN 0021-9258.

Kolch W. (2005). Coordinating ERK/MAPK signalling through scaffolds and inhibitors. Nature Reviews Molecular Cell Biology. 6, pp.827-837. ISSN 1471-0072.

Kreppel, L.K.; Blomberg, M.A. \& Hart, G.W. (1997). Dynamic glycosylation of nuclear and cytosolic proteins. Cloning and characterization of a unique O-GlcNAc transferase with multiple tetratricopeptide repeats. Journal of Biological Chemistry. 272, pp.93089315. ISSN 0021-9258.

Kreppel, L.K. \& Hart, G.W. (1999). Regulation of a cytosolic and nuclear O-GlcNAc transferase. Role of the tetratricopeptide repeats. Journal of Biological Chemistry. 274, pp.32015-32022. ISSN 0021-9258.

Laczy, B.; Hill, B.G.; Wang, K.; Paterson, A.J.; White, C.R.; Xing, D.; Chen, Y.F.; DarleyUsmar, V.; Oparil, S. \& Chatham, J.C. (2009). Protein O-GlcNAcylation: a new signaling paradigm for the cardiovascular system. American Journal of Physiology (Heart and Circulatory Physiology). 296, pp.H13-H28. ISSN 0363-6135.

Lameira, J.; Alves, C.N.; Tunon, I.; Marti, S. \& Moliner, V. (2011). Enzyme molecular mechanism as a starting point to design new inhibitors: a theoretical study of OGlcNAcase. The Journal of Physical Chemistry B. 115, pp.6764-6775. ISSN 1520-6106.

Lazarus, B.D.; Love, D.C. \& Hanover, J.A. (2006). Recombinant O-GlcNAc transferase isoforms: identification of O-GlcNAcase, yes tyrosine kinase, and tau as isoformspecific substrates. Glycobiology. 16, pp.415-421. ISSN 0959-6658.

Lazarus, M.B.; Nam, Y.; Jiang, J.; Sliz, P. \& Walker, S. (2011). Structure of human O-GlcNAc transferase and its complex with a peptide substrate. Nature. 469, pp.564-567. ISSN 0028-0836.

Li, S.Y.; Sigmon, V.K.; Babcock, S.A. \& Ren, J. (2007). Advanced glycation endproduct induces ROS accumulation, apoptosis, MAP kinase activation and nuclear O-GlcNAcylation in human cardiac myocytes. Life Sciences. 80, pp.1051-1056. ISSN 0024-3205.

Li, T.; Guo, L.; Zhang, Y.; Wang, J.; Li, Z.; Lin, L.; Zhang, Z.; Li, L.; Lin, J.; Zhao, W.; Li, J. \& Wang, P.G. (2011). Design and synthesis of O-GlcNAcase inhibitors via 'click chemistry' and biological evaluations. Carbohydrate Research. 346, pp.1083-1092. ISSN 0008-6215.

Lima, V.V.; Rigsby, C.S.; Hardy, D.M.; Webb, R.C. \& Tostes, R.C. (2009). O-GlcNAcylation: a novel post-translational mechanism to alter vascular cellular signaling in health and disease: focus on hypertension. Journal of the American Society of Hypertension. 3 , pp.374-387. ISSN 1933-1711.

Lima, V.V.; Giachini, F.R.; Carneiro, F.S.; Carvalho, M.H.; Fortes, Z.B.; Webb, R.C. \& Tostes, R.C. (2011). O-GlcNAcylation contributes to the vascular effects of ET-1 via activation of the RhoA/Rho-kinase pathway. Cardiovascular Research. 89, pp.614622. ISSN 0008-6363.

Lima, V.V.; Giachini, F.R.; Hardy, D.M.; Webb, R.C. \& Tostes, R.C. (2011). O-GlcNAcylation: a novel pathway contributing to the effects of endothelin in the vasculature. 
American Jounral of Physiology (Regulatory and Integrative Comparative Physiology). 300, pp.R236-R250. ISSN 0363-6119.

Lubas, W.A. \& Hanover, J.A. (2000). Functional expression of O-linked GlcNAc transferase. Domain structure and substrate specificity. Journal of Biological Chemisty. 275, pp.10983-10988. ISSN 0021-9258.

Macauley, M.S. \& Vocadlo, D.J. (2010). Increasing O-GlcNAc levels: An overview of smallmolecule inhibitors of O-GlcNAcase. Biochimica et Biophysica Acta. 1800, pp.107-121. ISSN 0006-3002.

Macauley, M.S.; Whitworth, G.E.; Debowski, A.W.; Chin, D. \& Vocadlo, D.J. (2005). OGlcNAcase uses substrate-assisted catalysis: kinetic analysis and development of highly selective mechanism-inspired inhibitors. Journal of Biological Chemisty. 280, pp.25313-25322. ISSN 0021-9258.

Martin GS. (2001). The hunting of the Src. Nature Reviews Molecular Cell Biology. 2, pp.467475. ISSN 1471-0072.

Martinez-Fleites, C.; He, Y. \& Davies, G.J. (2010). Structural analyses of enzymes involved in the O-GlcNAc modification. Biochimica et Biophysica Acta. 1800, pp.122-133. ISSN 0006-3002.

Matthews, J.A.; Acevedo-Duncan, M. \& Potter, R.L. (2005). Selective decrease of membraneassociated PKC-alpha and PKC-epsilon in response to elevated intracellular OGlcNAc levels in transformed human glial cells. Biochimica et Biophysica Acta 1743, pp.305-315. ISSN 0006-3002.

Mishra, S.; Ande, S.R. \& Salter, N.W. (2011). O-GlcNAc modification: why so intimately associated with phosphorylation? Cell Communication \& Signaling. 9, p.1. ISSN 1478811X.

Musicki, B.; Kramer, M.F.; Becker, R.E. \& Burnett, A.L. (2005). Inactivation of phosphorylated endothelial nitric oxide synthase (Ser-1177) by O-GlcNAc in diabetes-associated erectile dysfunction. Proceedings of the National Academy of Sciences USA 102, pp.11870-11875. ISSN 1091-6490.

Nandi, A.; Sprung, R.; Barma, D.K.; Zhao, Y.; Kim, S.C. \& Falck, J.R. (2006). Global identification of O-GlcNAc-modified proteins. Analytical Chemistry. 78, pp.452-458. ISSN 0003-2700.

Nolte, D. \& Muller, U. (2002). Human O-GlcNAc transferase (OGT): genomic structure, analysis of splice variants, fine mapping in Xq13.1. Mammalian Genome. 13, pp.6264. ISSN 0938-8990.

Oda, Y.; Renaux, B.; Bjorge, J.; Saifeddine, M.; Fujita, D.J. \& Hollenberg, M.D. (1999). c-Src is a major cytosolic tyrosine kinase in vascular tissue. Canadian Journal of Physiology and Pharmacology. 77, pp.606-617. ISSN 0008-4212.

Olszewski, N.E.; West, C.M.; Sassi, S.O. \& Hartweck, L.M. (2009). O-GlcNAc protein modification in plants: Evolution and function. Biochimica et Biophysica Acta. 1800, pp.49-56. ISSN 0006-3002.

Pearson, G.; Robinson, F.; Beers Gibson, T.; Xu, B.E.; Karandikar, M.; Berman, K. \& Cobb, M.H. (2001). Mitogen-activated protein (MAP) kinase pathways: regulation and physiological functions. Endocrine Reviews 22, pp.153-183. ISSN 0163-769X.

Peter-Katalinic, J. (2005). Methods in enzymology: O-glycosylation of proteins. Methods in Enzymology 405, pp.139-171. ISSN 0076-6879.

Rexach, J.E.; Clark, P.M. \& Hsieh-Wilson, L.C. (2008). Chemical approaches to understanding O-GlcNAc glycosylation in the brain. Nature Chemical Biology. 4, pp.97-106. ISSN 1552-4450. 
Robles-Flores, M.; Melendez, L.; Garcia, W.; Mendoza-Hernandez, G.; Lam, T.T.; CastanedaPatlan, C. \& Gonzalez-Aguilar, H. (2008). Posttranslational modifications on protein kinase c isozymes. Effects of epinephrine and phorbol esters. Biochimica et Biophysica Acta 1783, pp.695-712. ISSN 0006-3002.

Rogers, S.; Wells, R. \& Rechsteiner, M. (1986). Amino acid sequences common to rapidly degraded proteins: the PEST hypothesis. Science. 234, pp.364-368. ISSN 0036-8075.

Salamanca, D.A. \& Khalil, R.A. (2005). Protein kinase C isoforms as specific targets for modulation of vascular smooth muscle function in hypertension. Biochemical Pharmacology. 70, pp.1537-1547. ISSN 0006-2952.

Sauzeau, V.; Le Jeune, H.; Cario-Toumaniantz, C.; Smolenski, A.; Lohmann, S.M.; Bertoglio, J.; Chardin, P.; Pacaud, P. \& Loirand, G. (2000). Cyclic GMP-dependent protein kinase signaling pathway inhibits RhoA-induced Ca2+ sensitization of contraction in vascular smooth muscle. Journal of Biological Chemistry. 275, pp.21722-21729. ISSN 0021-9258.

Sawada, N.; Itoh, H.; Yamashita, J.; Doi, K.; Inoue, M.; Masatsugu, K.; Fukunaga, Y.; Sakaguchi, S.; Sone, M.; Yamahara, K.; Yurugi, T. \& Nakao, K. (2001). cGMPdependent protein kinase phosphorylates and inactivates RhoA. Biochemical and Biophysical Research Communication. 280, pp.798-805. ISSN 0006-291X.

Slawson, C.; Copeland, R.J. \& Hart, G.W. (2010). O-GlcNAc signaling: a metabolic link between diabetes and cancer? Trends in Biochemical Sciences. 35, pp.547-555. ISSN 0968-0004.

Somlyo, A.P. \& Somlyo, A.V. (2000). Signal transduction by G-proteins, rho-kinase and protein phosphatase to smooth muscle and non-muscle myosin II. Journal of Physiology. 522, Pt 2, pp.177-185. ISSN 0022-3751.

Spiro, R.G. (2002) Protein glycosylation: nature, distribution, enzymatic formation, and disease implications of glycopeptide bonds. Glycobiology. 12, pp.43R-56R. ISSN 0959-6658.

Swain, S.M.; Tseng, T.S. \& Olszewski, N.E. (2001). Altered expression of SPINDLY affects gibberellin response and plant development. Plant Physiology. 126, pp.1174-1185. ISSN 0032-0889.

Taylor, M.E. \& Drickamer, K. (2006). Introduction to glycobiology / Maureen E. Taylor, Kurt Drickamer. 2nd ed. Oxford, New York. Oxford University Press. xix, 255 p. : ill. ISBN-10: 0199258686.

Toleman, C.; Paterson, A.J.; Whisenhunt, T.R. \& Kudlow, J.E. (2004). Characterization of the histone acetyltransferase (HAT) domain of a bifunctional protein with activable OGlcNAcase and HAT activities. Journal of Biological Chemistry. 279, pp.53665-53673. ISSN 0021-9258.

Torres, C.R. \& Hart, G.W. (1984). Topography and polypeptide distribution of terminal Nacetylglucosamine residues on the surfaces of intact lymphocytes. Evidence for Olinked GlcNAc. Journal of Biological Chemistry. 259, pp.3308-3317. ISSN 0021-9258.

Varki, A.; Cummings, R.D.; Esko, J.D.; Freeze, H.H.; Stanley, P.; Bertozzi, C.R.; Hart, G.W. \& Etzler, M.E. (2009). Essentials of Glycobiology. 2nd edition ed, ed. T.C.o.G. Editors: Cold Spring Harbor (NY): Cold Spring Harbor Laboratory Press. ISBN-13: 9780879697709.

Vosseller, K.; Trinidad, J.C.; Chalkley, R.J.; Specht, C.G.; Thalhammer, A.; Lynn, A.J.; Snedecor, J.O.; Guan, S.; Medzihradszky, K.F.; Maltby, D.A.; Schoepfer, R. \& Burlingame, A.L. (2006). O-linked $\mathrm{N}$-acetylglucosamine proteomics of postsynaptic 
density preparations using lectin weak affinity chromatography and mass spectrometry. Molecular and Cellular Proteomics. 5, pp.923-934. ISSN 1535-9476.

Wang, Z.; Udeshi, N.D.; O'Malley, M.; Shabanowitz, J.; Hunt, D.F. \& Hart, G.W. (2010). Enrichment and site mapping of O-linked N-acetylglucosamine by a combination of chemical/enzymatic tagging, photochemical cleavage, and electron transfer dissociation mass spectrometry. Molecular and Cellular Proteomics. 9, pp.153-160. ISSN 1535-9476.

Wang, J.; Liu, R.; Hawkins, M.; Barzilai, N. \& Rossetti, L. (1998). A nutrient-sensing pathway regulates leptin gene expression in muscle and fat. Nature. 393, pp.684-688. ISSN 0028-0836.

Wang, J.; Torii, M.; Liu, H.; Hart, G.W. \& Hu, Z.Z. (2011). dbOGAP - an integrated bioinformatics resource for protein O-GlcNAcylation. BMC Bioinformatics. 12, pp.91. ISSN 1471-2105.

Wang, Z.; Gucek, M. \& Hart, G.W. (2008). Cross-talk between GlcNAcylation and phosphorylation: site-specific phosphorylation dynamics in response to globally elevated O-GlcNAc. Proceedings of the National Academy of Sciences USA. 105, pp.13793-13798. ISSN 1091-6490.

Wang, Z.; Pandey, A. \& Hart, G.W. (2007). Dynamic interplay between O-linked Nacetylglucosaminylation and glycogen synthase kinase-3-dependent phosphorylation. Molecular and Cellular Proteomics. 6, pp.1365-1379. ISSN 1535-9476.

Wells, L.; Gao, Y.; Mahoney, J.A.; Vosseller, K.; Chen, C.; Rosen, A. \& Hart, G.W. (2002). Dynamic O-glycosylation of nuclear and cytosolic proteins: further characterization of the nucleocytoplasmic beta-N-acetylglucosaminidase, O-GlcNAcase. Journal of Biological Chemistry. 277, pp.1755-1761. ISSN 0021-9258.

Wells, L.; Kreppel, L.K.; Comer, F.I.; Wadzinski, B.E. \& Hart, G.W. (2004). O-GlcNAc transferase is in a functional complex with protein phosphatase 1 catalytic subunits. Journal of Biological Chemistry. 279, pp.38466-38470. ISSN 0021-9258.

Woodsome, T.P.; Eto, M.; Everett, A.; Brautigan, D.L. \& Kitazawa, T. (2001). Expression of $\mathrm{CPI}-17$ and myosin phosphatase correlates with $\mathrm{Ca}(2+)$ sensitivity of protein kinase C-induced contraction in rabbit smooth muscle. Journal of Physiology. 535, pp.553564. ISSN 0022-3751.

Yang, W.H.; Kim, J.E.; Nam, H.W.; Ju, J.W.; Kim, H.S.; Kim, Y.S. \& Cho, J.W. (2006). Modification of p53 with O-linked $\mathrm{N}$-acetylglucosamine regulates p53 activity and stability. Nature Cell Biology. 8, pp.1074-1083. ISSN 1465-7392.

Zachara, N.E. (2009). Detecting the "O-GlcNAc-ome"; detection, purification, and analysis of O-GlcNAc modified proteins. Methods in Molecular Biology. 534, pp.251-279. ISSN 1064-3745.

Zachara, N.E. \& Hart, G.W. (2006). Cell signaling, the essential role of O-GlcNAc! Biochimica et Biophysica Acta. 1761, pp.599-617. ISSN 0006-3002.

Zeidan, Q. \& Hart, G.W. (2010). The intersections between O-GlcNAcylation and phosphorylation: implications for multiple signaling pathways. Journal of Cell Science. 123, pp.13-22. ISSN 0021-9533.

Zou, L.; Yang, S.; Champattanachai, V.; Hu, S.; Chaudry, I.H.; Marchase, R.B. \& Chatham, J.C. (2009). Glucosamine improves cardiac function following trauma-hemorrhage by increased protein O-GlcNAcylation and attenuation of NF-\{kappa\}B signaling. American Journal of Physiology (Heart and Circulatory Physiology). 296, pp.H515H523. ISSN 0363-6135. 


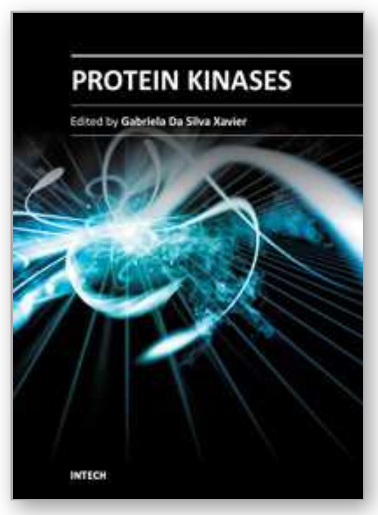

\author{
Protein Kinases \\ Edited by Dr. Gabriela Da Silva Xavier
}

ISBN 978-953-51-0640-1

Hard cover, 484 pages

Publisher InTech

Published online 05, June, 2012

Published in print edition June, 2012

Proteins are the work horses of the cell. As regulators of protein function, protein kinases are involved in the control of cellular functions via intricate signalling pathways, allowing for fine tuning of physiological functions. This book is a collaborative effort, with contribution from experts in their respective fields, reflecting the spirit of collaboration - across disciplines and borders - that exists in modern science. Here, we review the existing literature and, on occasions, provide novel data on the function of protein kinases in various systems. We also discuss the implications of these findings in the context of disease, treatment, and drug development.

\title{
How to reference
}

In order to correctly reference this scholarly work, feel free to copy and paste the following:

Victor V. Lima and Rita C. Tostes (2012). Alternating Phosphorylation with O-GlcNAc Modification: Another Way to Control Protein Function, Protein Kinases, Dr. Gabriela Da Silva Xavier (Ed.), ISBN: 978-953-51-06401, InTech, Available from: http://www.intechopen.com/books/protein-kinases/alternating-phosphorylation-witho-glcnac-modification-another-way-to-control-protein-function

\section{INTECH}

open science | open minds

\section{InTech Europe}

University Campus STeP Ri

Slavka Krautzeka 83/A

51000 Rijeka, Croatia

Phone: +385 (51) 770447

Fax: +385 (51) 686166

www.intechopen.com

\section{InTech China}

Unit 405, Office Block, Hotel Equatorial Shanghai

No.65, Yan An Road (West), Shanghai, 200040, China

中国上海市延安西路65号上海国际贵都大饭店办公楼405单元

Phone: +86-21-62489820

Fax: +86-21-62489821 
(C) 2012 The Author(s). Licensee IntechOpen. This is an open access article distributed under the terms of the Creative Commons Attribution 3.0 License, which permits unrestricted use, distribution, and reproduction in any medium, provided the original work is properly cited. 